Research Article

\title{
Comparison of Mask Oxygen Therapy and High-Flow Oxygen Therapy after Cardiopulmonary Bypass in Obese Patients
}

\author{
Mazlum Sahin (D), ${ }^{1}$ Helin El, ${ }^{2}$ and Ibrahim Akkoç ${ }^{3}$ \\ ${ }^{1}$ Department of Cardiovascular Surgery, Haseki Teaching and Research Hospital, Istanbul, Turkey \\ ${ }^{2}$ Department of Cardiovascular Surgery, Sisli Teaching and Research Hospital, Istanbul, Turkey \\ ${ }^{3}$ Department of Anesthesia and Reanimation, Haseki Teaching and Research Hospital, Istanbul, Turkey \\ Correspondence should be addressed to Mazlum Sahin; mzlmshn@gmail.com
}

Received 23 September 2017; Accepted 26 November 2017; Published 28 January 2018

Academic Editor: Panfeng Fu

Copyright ( 2018 Mazlum Sahin et al. This is an open access article distributed under the Creative Commons Attribution License, which permits unrestricted use, distribution, and reproduction in any medium, provided the original work is properly cited.

\begin{abstract}
Background. To clarify the efficiency of mask $\mathrm{O}_{2}$ and high-flow $\mathrm{O}_{2}$ (HFO) treatments following cardiopulmonary bypass (CPB) in obese patients. Methods. During follow-up, oxygenization parameters including arterial pressure of oxygen $\left(\mathrm{PaO}_{2}\right)$, peripheral oxygen saturation $\left(\mathrm{SpO}_{2}\right)$, and arterial partial pressure of carbon dioxide $\left(\mathrm{PaCO}_{2}\right)$ and physical examination parameters including respiratory rate, heart rate, and arterial pressure were recorded respectively. Presence of atelectasia and dyspnea was noted. Also, comfort scores of patients were evaluated. Results. Mean duration of hospital stay was $6.9 \pm 1.1$ days in the mask $\mathrm{O}_{2}$ group, whereas the duration was significantly shorter $(6.5 \pm 0.7$ days $)$ in the HFO group $(p=0.034)$. The $\mathrm{PaO}_{2}$ values and $\mathrm{SpO}_{2}$ values were significantly higher, and $\mathrm{PaCO}_{2}$ values were significantly lower in patients who received HFO after 4th, 12th, 24th, 36th, and 48th hours. In postoperative course, HFO leads patients to achieve better postoperative FVC $(p<0.001)$. Also, dyspnea scores and comfort scores were significantly better in patients who received HFO in both postoperative day 1 and day 2 $(p<0.001, p<0.001$ and $p=0.002, p=0.001$, resp.). Conclusion. Our study demonstrated that HFO following CPB in obese patients improved postoperative $\mathrm{PaO}_{2}, \mathrm{SpO}_{2}$, and $\mathrm{PaCO}_{2}$ values and decreased the atelectasis score, reintubation, and mortality rates when compared with mask $\mathrm{O}_{2}$.
\end{abstract}

\section{Introduction}

According to World Health Organization, obesity is defined as excessive and abnormal fat accumulation that creates risk for health, and a person with a body mass index (BMI) greater than or equal to $30 \mathrm{~kg} / \mathrm{m}^{2}$ is considered obese [1]. Incidence of sedentary lifestyle with high-fat diet intake and comorbidities including metabolic syndrome, diabetes mellitus, and hypertension are common among obese patients. Also, it is well known that obesity and obesityrelated disorders are risk factors for severe coronary artery diseases which may require cardiopulmonary bypass (CPB) [2]. Additionally, obese patients are more vulnerable to pulmonary complications following $\mathrm{CPB}$ due to decreased total lung capacity, functional residual capacity, forced vital capacity, and expiratory reserve volume.
Moreover, anesthetic agents and sedatives aggravate the respiratory instability in obese patients [3].

Previous studies had demonstrated that severe hypoxemia, hypercapnia, and prolonged apnea periods deteriorate healing after $\mathrm{CPB}$. To avoid these undesirable conditions, some authors recommended oxygen therapy which had a key role in improving respiratory functions and patient comfort by decreasing desaturation episodes and reintubation rates after cardiac surgery $[4,5]$. In a prospective randomized study, Zhu et al. showed significant reduction of the reintubation rate after cardiac surgery with mask $\mathrm{O}_{2}$ [5]. In contrast, Stéphan et al. reported insufficiency of mask $\mathrm{O}_{2}$ therapy for oxygen treatment following cardiac surgerysupported high-flow $\mathrm{O}_{2}$ (HFO) treatment [6]. Therefore, the most appropriate method of oxygen therapy is still under investigation, especially in obese patients who are at high risk for respiratory problems following $\mathrm{CPB}$. 
Although previous studies investigated the role of mask $\mathrm{O}_{2}$ and HFO treatments following CPB, none of these studies have compared these two different treatment modalities in patients with BMI more than $30 \mathrm{~kg} / \mathrm{m}^{2}$. In this study, we, for the first time, aimed to clarify the importance of mask $\mathrm{O}_{2}$ and $\mathrm{HFO}$ treatments following $\mathrm{CPB}$ in obese patients.

\section{Materials and Methods}

In this prospective randomized study, charts of patients who underwent $\mathrm{CABG}$ in a tertiary academic center between January 2015 and January 2017 were analyzed. Ethical approval for the study was obtained from the Haseki Teaching and Research Hospital's Regional Ethical Committee, with study ID number 499 . Patients with $\mathrm{BMI}>30 \mathrm{~kg} / \mathrm{m}^{2}$ were enrolled in the study. Randomization was done by a computer-based random number-sequencing program. Exclusion criteria were hemodynamic instability, patients younger than 18 years of age, and patients with tracheostomy, obstructive sleep apnea, and active pulmonary disease. Also, patients with low cardiac output and operations who were held under emergency conditions were excluded from the study. Written consent was obtained from patients and/or relatives.

2.1. Study protocol. In Cardiovascular Surgery Intensive Care Unit (ICU), every patient, who underwent CABG, was followed up by a well-trained ICU nurse and a cardiovascular surgeon in the postoperative period. Hemodynamically stable patients, who had a sufficient oxygenation $\left(\mathrm{SpO}_{2}\right.$ (peripheral oxygen saturation) $>92, \mathrm{FiO}_{2}$ (fraction of inspired oxygen) $\leq$ 0.4 , PEEP (positive end-expiratory pressure) $\leq 8 \mathrm{mmHg}$, and $\mathrm{PaO}_{2}$ (arterial pressure of oxygen) $/ \mathrm{FiO}_{2} \geq 150$ ), were weaned by the spontaneous breathing trial (SBT) with low-level pressure support or oxygen T-piece for 90-120 minutes. Endotracheal extubation was performed in patients who have tolerated the SBT.

After endotracheal extubation, patients were randomly divided into two groups. In patients $(n=50)$ who received $\mathrm{HFO}$ treatment, high-flow humidified oxygen $\left(44 \mathrm{~mm} / \mathrm{H}_{2} \mathrm{O} / \mathrm{L}\right.$ and $37^{\circ} \mathrm{C}$ ) was released through a nasal cannula continuously with Optiflow (Vapotherm, New Hampshire, USA). The preliminary flow rate was $25-40 \mathrm{~L} / \mathrm{min}$, and the initial $\mathrm{FiO}_{2}$ was $50 \%$ to maintain $\mathrm{SaO}_{2}>93$. In the other group $(n=50$ patients) who underwent oxygen therapy, oxygen was delivered from a simple face mask (Orya Medikal, Istanbul, Turkey) with a flow of 2-4 liters in a minute to maintain $\mathrm{SpO}_{2}>93 \%$. Active respiratory physiotherapy was performed for all patients during the postoperative period. The patients were encouraged for early mobilization.

2.2. Atelectasis Scoring. Presence of atelectasis was evaluated by a postoperative chest X-ray and classified according to the radiological atelectasis score system (RAS) [7]. The RAS is divided into five categories (0: clear lung fields, 1: plate-like atelectasis or slight infiltration, 2: partial atelectasis, 3: lobar atelectasis, and 4: bilateral atelectasis), and chest X-rays were evaluated by a single radiologist who was blinded to mask $\mathrm{O}_{2}$ and HFO outcomes.
After the surgery, respiratory parameters and physical examination findings were recorded in 4th, 12th, 24th, 36th, and 48th hours, respectively. Patients' comfort and relief was evaluated once per day (1, very poor; 2 , poor; 3 , sufficient; 4 , good; and 5, very good). Also, patients were assessed about the effectiveness of treatment once per day (2, marked improvement; 1 , slight improvement; 0 , no change; -1 , slight deterioration; and -2 , marked deterioration) [6].

Discontinuation of mask $\mathrm{O}_{2}$ or HFO therapy due to the side effects, requirement of additional treatment, or necessity of reintubation for mechanical ventilation was accepted as failure of the current treatment. Reintubation criteria were cardiovascular instability, respiratory arrest or respiratory acidosis $\left(\mathrm{pH}<7.30\right.$ and $\mathrm{PaCO}_{2} \geq 50 \mathrm{mmHg}$ ), encephalopathy, and clinical findings of exhaustion and refractory hypoxemia (arterial oxygen saturation $<88 \%$ with $\mathrm{FiO}_{2}=100 \%$ ). Reintubation was performed according to the physician's decision, if required. The length of ICU and hospital stay was recorded. Lastly, respiratory complications, extrapulmonary complications, and presence of mortality were documented.

During statistical analyses, values were evaluated as numbers, means, percentages, and intervals. Numbers and percentages were compared using the chi-square test. Before the comparison of means of values, the values were evaluated for homogeneity. Homogeneously distributed values were compared using Student's $t$-test, and heterogeneously distributed values were compared using the Mann-Whitney $U$ test.

\section{Results}

During the study period, 137 patients underwent the CABG procedure, and 100 patients were enrolled in the study. Other 37 patients were excluded from the study according to study exclusion criteria (Figure 1). These patients were divided into two groups; 50 patients were treated with mask $\mathrm{O}_{2}$, and 50 patients were treated with HFO. The mean age was $61.3 \pm 8.5$ in patients who received mask $\mathrm{O}_{2}$ and $62.0 \pm 6.7$ in patients who received HFO $(p=0.660)$. Sex, BMI, and history of smoking were similar between groups $(p=1.000$, $p=0.259$, and $p=0.842$, resp.). The operative parameters in terms of duration of surgery, myocardial ischemia period, and extubation time were comparable between patients who received mask $\mathrm{O}_{2}$ and $\mathrm{HFO}(p=0.709, p=0.740$, and $p=0.529$, resp.). Preoperative and operative parameters are summarized in Table 1.

Among the patients who have received mask $\mathrm{O}_{2}, 11$ patients required continuous positive airway pressure (CPAP) and four patients required reintubation due to the increased arterial carbon dioxide value and mental deterioration despite extensive pulmonary rehabilitation maneuvers. In patients who have received $\mathrm{HFO}, \mathrm{CPAP}$ was required in six patients; however, none of these patients required reintubation $(p=0.187$ and $p<0.001)$. The duration of ICU stay was $2.8 \pm 1.7$ days in patients with mask $\mathrm{O}_{2}$ and $2.4 \pm 0.5$ days in patients with HFO $(p=0.130)$. The duration of hospital stay was $6.9 \pm 1.1$ days in the mask $\mathrm{O}_{2}$ group, whereas it was significantly shorter $(6.5 \pm 0.7$ days $)$ in the HFO group 


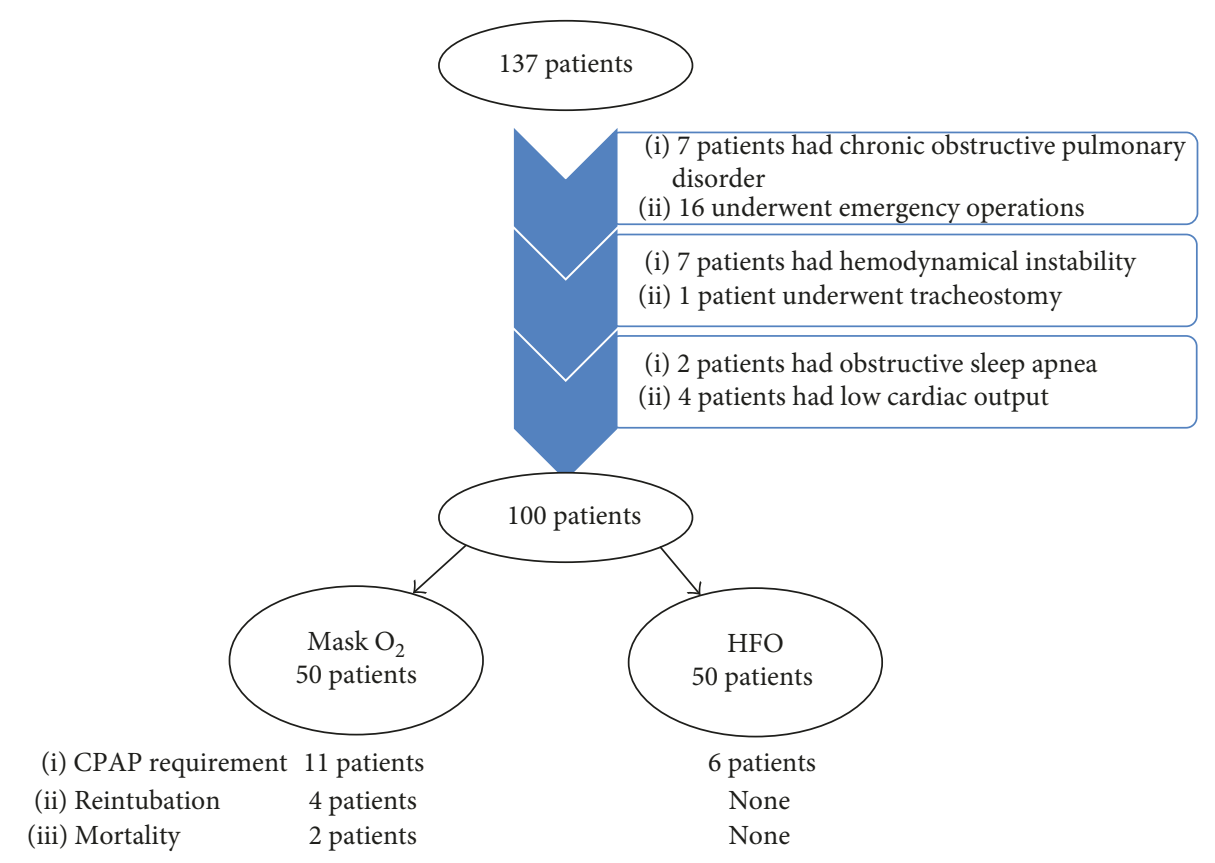

Figure 1: Flow chart scheme of the study.

TABle 1: Preoperative and operative characteristics of patients.

\begin{tabular}{|c|c|c|c|}
\hline & \multicolumn{2}{|c|}{ Group } & \multirow{2}{*}{$p$ value } \\
\hline & Mask $\mathrm{O}_{2}(n=50)$ & High-flow $\mathrm{O}_{2}(n=50)$ & \\
\hline Sex (female/male) & $32 / 18$ & $32 / 18$ & 1.000 \\
\hline Age (years)* & $61.3 \pm 8.5$ & $62.0 \pm 6.7$ & 0.660 \\
\hline Body mass index $\left(\mathrm{kg} / \mathrm{m}^{2}\right)^{*}$ & $32.3 \pm 1.1$ & $32.5 \pm 1.2$ & 0.259 \\
\hline \multicolumn{4}{|l|}{ Comorbidities } \\
\hline Diabetes mellitus & 20 & 19 & 0.840 \\
\hline Hypertension & 29 & 30 & 0.841 \\
\hline Chronic kidney disease & 3 & 3 & 1.000 \\
\hline Smoking history & 21 & 22 & 0.842 \\
\hline Ejection fraction $(\%)^{*}$ & $51.3 \pm 6.8$ & $50.3 \pm 6.2$ & 0.445 \\
\hline Number of CPB* & $3.2 \pm 0.7$ & $3.2 \pm 0.7$ & 0.786 \\
\hline CPB duration $(\min )^{*}$ & $90.5 \pm 12.1$ & $91.4 \pm 13.0$ & 0.709 \\
\hline Clamping duration $(\min )^{*}$ & $41.0 \pm 11.8$ & $41.8 \pm 12.8$ & 0.740 \\
\hline Duration of extubation (hour) ${ }^{*}$ & $8.2 \pm 4.3$ & $7.8 \pm 1.4$ & 0.529 \\
\hline
\end{tabular}

${ }^{*}$ Mean \pm standard deviation; CPB: cardiopulmonary bypass; min: minutes.

$(p=0.034)$. Moreover, the atrial fibrillation rate and mortality rate were significantly lower in patients who were treated with HFO $(p<0.001$ and $p<0.001$, resp.). Death was observed in only two patients who have received mask $\mathrm{O}_{2}$ (Table 2 ).

The respiratory parameters $\mathrm{PaO}_{2}$ value and $\mathrm{SpO}_{2}$ value were significantly higher and $\mathrm{PaCO}_{2}$ value was significantly lower in patients who have received HFO. The $\mathrm{PaO}_{2}$ value was $104.3 \pm 5.6,96.2 \pm 7.4,96.6 \pm 6.7,97.1 \pm 6.3$, and $99.4 \pm 7.1$ after 4 th, 12th, 24th, 36th, and 48th hours in patients with mask $\mathrm{O}_{2}$ and $112.3 \pm 8.8,106.9 \pm 7.5,100.0 \pm$ $4.5,104.9 \pm 5.9$, and $106.0 \pm 6.9$ after 4 th, 12 th, 24 th, 36th, and 48th hours in patients with HFO $(p<0.001, p<0.001$, $p=0.004, p<0.001$, and $p<0.001$, resp.). Similarly, $\mathrm{SpO}_{2}$ values were $98.0 \pm 0.7,97.5 \pm 1.1,97.4 \pm 4.3,97.5 \pm 1.2$, and $97.5 \pm 1.2$ after 4 th, 12th, 24th, 36th, and 48th hours in patients with HFO. $\mathrm{SpO}_{2}$ values were statistically better in patients who have received HFO when compared with the mask $\mathrm{O}_{2}$ group $(p<0.001, p<0.001, p=0.001, p<0.001$, and $p<0.001$, resp.). In contrast, patients with mask $\mathrm{O}_{2}$ faced with worse $\mathrm{PaCO}_{2}$ values (43.1 \pm 2.8 versus $41.2 \pm 2.1,43.7 \pm$ 1.9 versus $41.2 \pm 2.1,43.5 \pm 1.8$ versus $40.7 \pm 2.2,43.3 \pm 1.6$ versus $39.3 \pm 2.8$, and $42.3 \pm 2.2$ versus $37.9 \pm 2.6$ after 4 th, 12th, 24th, 36th, and 48th hours, resp.). The mean heart rate was significantly lower in the HFO group in 4 th, 12th, 24th, and 36th hours after CPB $(p<0.001, p=0.009, p=0.001$, 
TABle 2: Postoperative complications, treatment failure, and mortality rates of patients.

\begin{tabular}{lccc}
\hline & \multicolumn{3}{c}{ Group } \\
& $\begin{array}{c}\text { Mask } \mathrm{O}_{2} \\
(n=50)\end{array}$ & $\begin{array}{c}\text { High-flow } \mathrm{O}_{2} \\
(n=50)\end{array}$ & $p$ value \\
\hline CPAP requirement & 11 & 6 & 0.187 \\
Reintubation & 4 & 0 & $<\mathbf{0 . 0 0 1}$ \\
Pneumonia & 2 & 0 & $<\mathbf{0 . 0 0 1}$ \\
ICU stay (day)* & $2.8 \pm 1.7$ & $2.4 \pm 0.5$ & 0.130 \\
Hospitalization & $6.9 \pm 1.1$ & $6.5 \pm 0.7$ & $\mathbf{0 . 0 3 4}$ \\
duration (day) $^{*}$ & 12 & 7 & $<\mathbf{0 . 0 0 1}$ \\
Atrial fibrillation & $1.8 \pm 0.7$ & $2.0 \pm 0.7$ & 0.080 \\
Transfusion rate* & 2 & 0 & $<\mathbf{0 . 0 0 1}$ \\
Mortality $^{*}$ & & 0 &
\end{tabular}

${ }^{*}$ Mean \pm standard deviation; CPAP: continuous positive airway pressure; ICU: intensive care unit.

and $p<0.001$, resp.). In addition, patients who have received HFO had higher blood pressure values in 4th and 12th hours $(98.0 \pm 2.2$ versus $94.5 \pm 3.3$ after 4 th hour and $98.0 \pm 2.2$ versus $96.1 \pm 3.2$ after 12 th hour). The respiratory rate following endotracheal extubation was significantly lower at the 4th hour in patients who have received HFO $(p<0.001)$; however, it did not differ significantly at the other follow-up intervals. Postoperative atelectasis score in the 4 th hour was similar between groups $(p=1.000)$; however, patients who have received HFO had significantly better atelectasis scores in 12th, 24th, 36th, and 48th hours $(p=0.004, p<0.001, p<0.001$, and $p<0.001$, resp.). Preoperative $\mathrm{FEV}_{1}$ (forced expiratory volume) and FVC (forced vital capacity) were comparable between groups ( $p=0.650$ and $p=0.228$ ). However, during postoperative follow-up, HFO leads patients to achieve better FVC $(p<0.001)$ values. The dyspnea scores were significantly better in patients with HFO in both postoperative day 1 and day $2(p<0.001$ and $p<0.001)$. The comfort scores of patients who have received HFO were better in postoperative day 1 and day 2 ( $p=0.002$ and $p=0.001$, resp.). Postoperative parameters are summarized in Tables 3 and 4 .

\section{Discussion}

Acute respiratory failure is still a challenging and lifethreatening complication in patients who underwent open heart surgery with CPB. During respiratory insufficiency, respiratory support is a critical step to maintain patient comfort, prevent invasive mechanical ventilation, and decrease mortality [8]. Therefore, choosing the most appropriate device for oxygen therapy is a crucial decision to maintain adequate oxygenation especially in patients who are at high risk for acute respiratory failure such as patients with sleep apnea syndrome, advanced stage heart failure, and high BMI.

Obese patients are prone to hypoxia development due to several risk factors. Obese patients have extensive adipose tissue with high metabolic activity that is associated with increased oxygen consumption and carbon dioxide production. Due to breathing difficulties in obese cases, supportive muscles spend more oxygen and produce more carbon dioxide to overcome the workload. Additionally, compliance of respiratory organs and lung volumes are decreased in obese patients [9]. Due to the lower resting functional residual capacity, obese patients have an increased respiratory rate to compensate the ventilationperfusion mismatch especially at the base of the lungs. Furthermore, postoperative atelectasis is common and more prominent in obese patients when compared with nonobese patients [10]. Thus, the best treatment modality to overcome postoperative oxygenation problems in obese patients is a critical problem and still under investigation.

The simple face mask and HFO nasal cannula are used for oxygen delivery in patients with hypoxia and/or hypercarbia. However, there is a trend in use of HFO especially in high-risk patients. Costello et al. stated that delivering oxygen through a face mask leads to dryness of the mouth and respiratory tract, and this situation leads to displacement of the face mask. Also, displacement of the mask is associated with the decrease in oxygen concentration [11]. On the other hand, HFO generates a dead space and creates a reservoir for oxygen in the respiratory system. In patients with tachypnea, delivered $\mathrm{O}_{2}$ may decrease due to the increased respiratory frequency, and HFO overcomes this by adequate and stable oxygenation. Moreover, $\mathrm{HFO}$ with positive pressure prevents the formation of atelectasis [12].

Previous reports on the efficiency of mask $\mathrm{O}_{2}$ and HFO in the management of acute respiratory failure had controversial results. Lemiale et al. investigated the effect of HFO in immunocompromised patients and found that HFO neither decreased the need for mechanical ventilation nor improved patients' quality of life [13]. In contrast, Schwabbauer et al. found significantly better dyspnea and patient comfort scores with HFO [12]. In another study, Maggiore et al. compared HFO and mask $\mathrm{O}_{2}$ in patients who were mechanically ventilated for more than 24 hours. They stated that high-flow $\mathrm{O}_{2}$ provided better oxygenation, fewer desaturation episodes, and lower reintubation rates [14]. Rittayamai et al. suggested HFO to overcome dyspnea and improve physiologic parameters [15]. In the present study, we achieved better $\mathrm{PaO}_{2}, \mathrm{SpO}_{2}$, and $\mathrm{PCO}_{2}$ levels in the first 48 hours with HFO in our obese patient cohort.

Pulmonary atelectasis is a common and undesired condition which is associated with oxygen impairment, decrease in lung compliance, increase in vascular resistance, and infectious complications [16]. To achieve more accurate classification of atelectasis and to evaluate treatment response, the Radiological Atelectasis Score was developed and validated. Parke et al. evaluated the effect of mask $\mathrm{O}_{2}$ and HFO by using Radiological Atelectasis Score, in 340 patients who underwent heart surgery. They claimed that prophylactic HFO improved the atelectasis scores [7]. Zarbock et al. analyzed 500 patients who underwent elective cardiac surgery and were supported by HFO to prevent atelectasis in the postoperative period [17]. In accordance with the literature, we have obtained better atelectasis scores in patients 
TABle 3: Postoperative respiratory characteristics, physical examination findings, and atelectasis scores of groups.

\begin{tabular}{|c|c|c|c|}
\hline & \multicolumn{2}{|c|}{ Group } & \multirow[b]{2}{*}{$\begin{array}{c}p \\
\text { value }\end{array}$} \\
\hline & $\begin{array}{l}\text { Mask } \mathrm{O}_{2} \\
(n=50)\end{array}$ & $\begin{array}{l}\text { High-flow } \mathrm{O}_{2} \\
\quad(n=50)\end{array}$ & \\
\hline \multicolumn{4}{|l|}{ Postoperative 4th hour* } \\
\hline $\mathrm{PaO}_{2}$ & $104.3 \pm 5.6$ & $112.3 \pm 8.8$ & $<0.001$ \\
\hline $\mathrm{SpO}_{2}$ & $96.8 \pm 1.3$ & $98.0 \pm 0.7$ & $<0.001$ \\
\hline $\mathrm{PaCO}_{2}$ & $43.1 \pm 2.8$ & $41.2 \pm 2.1$ & $<0.001$ \\
\hline Heart rate (beats/min) & $105.7 \pm 8.0$ & $98.4 \pm 3.3$ & $<0.001$ \\
\hline $\begin{array}{l}\text { Mean arterial pressure } \\
(\mathrm{mmHg})\end{array}$ & $94.5 \pm 3.3$ & $98.0 \pm 2.2$ & $<0.001$ \\
\hline $\begin{array}{l}\text { Respiratory rate } \\
\text { (breaths/min) }\end{array}$ & $21.6 \pm 1.6$ & $20.2 \pm 0.8$ & $<0.001$ \\
\hline Atelectasis score & $1 \pm 0$ & $1 \pm 0$ & 1.000 \\
\hline \multicolumn{4}{|l|}{$\begin{array}{l}\text { Postoperative 12th } \\
\text { hour* }\end{array}$} \\
\hline $\mathrm{PaO}_{2}$ & $96.2 \pm 7.4$ & $106.9 \pm 7.5$ & $<0.001$ \\
\hline $\mathrm{SpO}_{2}$ & $95.7 \pm 1.4$ & $97.5 \pm 1.1$ & $<0.001$ \\
\hline $\mathrm{PaCO}_{2}$ & $43.7 \pm 1.9$ & $41.2 \pm 2.1$ & $<0.001$ \\
\hline Heart rate (beats/min) & $99.3 \pm 6.1$ & $96.4 \pm 3.3$ & 0.009 \\
\hline $\begin{array}{l}\text { Mean arterial pressure } \\
(\mathrm{mmHg})\end{array}$ & $96.1 \pm 3.2$ & $98.0 \pm 2.2$ & 0.001 \\
\hline $\begin{array}{l}\text { Respiratory rate } \\
\text { (breaths/min) }\end{array}$ & $20.1 \pm 1.9$ & $20.0 \pm 0.9$ & 0.845 \\
\hline Atelectasis score & $1.7 \pm 0.5$ & $1.4 \pm 0.5$ & 0.004 \\
\hline \multicolumn{4}{|l|}{$\begin{array}{l}\text { Postoperative 24th } \\
\text { hour* }\end{array}$} \\
\hline $\mathrm{PaO}_{2}$ & $96.6 \pm 6.7$ & $100.0 \pm 4.5$ & 0.004 \\
\hline $\mathrm{SpO}_{2}$ & $95.7 \pm 1.3$ & $97.4 \pm 4.3$ & 0.001 \\
\hline $\mathrm{PaCO}_{2}$ & $43.5 \pm 1.8$ & $40.7 \pm 2.2$ & $<0.001$ \\
\hline Heart rate (beats/min) & $100.7 \pm 4.4$ & $97.5 \pm 4.9$ & 0.001 \\
\hline $\begin{array}{l}\text { Mean arterial pressure } \\
(\mathrm{mmHg})\end{array}$ & $96.6 \pm 2.5$ & $97.7 \pm 6.5$ & 0.277 \\
\hline $\begin{array}{l}\text { Respiratory rate } \\
\text { (breaths/min) }\end{array}$ & $19.9 \pm 1.7$ & $19.9 \pm 0.8$ & 0.697 \\
\hline Atelectasis score & $2.2 \pm 0.5$ & $1.7 \pm 0.7$ & $<0.001$ \\
\hline \multicolumn{4}{|l|}{$\begin{array}{l}\text { Postoperative } 36 \text { th } \\
\text { hour }\end{array}$} \\
\hline $\mathrm{PaO}_{2}$ & $97.1 \pm 6.3$ & $104.9 \pm 5.9$ & $<0.001$ \\
\hline $\mathrm{SpO}_{2}$ & $95.8 \pm 1.2$ & $97.5 \pm 1.2$ & $<0.001$ \\
\hline $\mathrm{PaCO}_{2}$ & $43.3 \pm 1.6$ & $39.3 \pm 2.8$ & $<0.001$ \\
\hline Heart rate (beats/min) & $100.6 \pm 4.5$ & $96.2 \pm 4.3$ & $<0.001$ \\
\hline $\begin{array}{l}\text { Mean arterial pressure } \\
(\mathrm{mmHg})\end{array}$ & $96.7 \pm 2.5$ & $95.4 \pm 4.9$ & 0.119 \\
\hline $\begin{array}{l}\text { Respiratory rate } \\
\text { (breaths/min) }\end{array}$ & $19.6 \pm 1.2$ & $19.4 \pm 0.9$ & 0.322 \\
\hline Atelectasis score & $2.2 \pm 0.5$ & $1.4 \pm 0.5$ & $<0.001$ \\
\hline \multicolumn{4}{|l|}{$\begin{array}{l}\text { Postoperative } 48 t h \\
\text { hour* }\end{array}$} \\
\hline $\mathrm{PaO}_{2}$ & $99.4 \pm 7.1$ & $106.0 \pm 6.9$ & $<0.001$ \\
\hline $\mathrm{SpO}_{2}$ & $95.7 \pm 1.3$ & $97.5 \pm 1.2$ & $<0.001$ \\
\hline $\mathrm{PaCO}_{2}$ & $42.3 \pm 2.2$ & $37.9 \pm 2.6$ & $<0.001$ \\
\hline Heart rate (beats/min) & $94.7 \pm 4.6$ & $95.1 \pm 3.5$ & 0.612 \\
\hline
\end{tabular}

TABle 3: Continued.

\begin{tabular}{lccc}
\hline & \multicolumn{2}{c}{ Group } & $p$ \\
& $\begin{array}{c}\text { Mask } \mathrm{O}_{2} \\
(n=50)\end{array}$ & $\begin{array}{c}\text { High-flow } \mathrm{O}_{2} \\
(n=50)\end{array}$ & $\begin{array}{c}p \\
\text { value }\end{array}$ \\
\hline $\begin{array}{l}\text { Mean arterial pressure } \\
\text { (mmHg) }\end{array}$ & $96.8 \pm 2.4$ & $97.0 \pm 2.2$ & 0.219 \\
$\begin{array}{l}\text { Respiratory rate } \\
\text { (breaths/min) }\end{array}$ & $19.5 \pm 1.1$ & $19.3 \pm 0.9$ & 0.451 \\
\begin{tabular}{l} 
Atelectasis score \\
\hline
\end{tabular} & $1.7 \pm 0.4$ & $1.3 \pm 0.5$ & $<\mathbf{0 . 0 0 1}$ \\
\hline
\end{tabular}

${ }^{*}$ Mean \pm standard deviation; $\mathrm{PaO}_{2}$ : arterial pressure of oxygen; $\mathrm{SpO}_{2}$ : peripheral oxygen saturation; $\mathrm{PaCO}_{2}$ : arterial partial pressure of carbon dioxide; min: minutes.

who received HFO. Thereby, we recommend HFO to prevent atelectasis in obese patients.

During oxygen therapy, patients' subjective response and patients' satisfaction have important roles in continuing oxygen treatment and mostly evaluated by scoring systems. Delclaux et al. analyzed patients who have received mask $\mathrm{O}_{2}$ treatment for acute hypoxemic respiratory insufficiency according to dyspnea scores. They found that applying $\mathrm{O}_{2}$ through a face mask had an impact on healing of dyspnea scores [18]. In another study by Stéphan et al., both mask $\mathrm{O}_{2}$ and HFO were found as beneficial tools to improve dyspnea scores to overcome hypoxia problem after cardiothoracic surgery. Also, Stéphan et al. emphasized that the two treatment modalities were not superior to each other according to dyspnea scores [6]. Kramer et al. demonstrated that $18 \%$ of mask $\mathrm{O}_{2}$ treatment failure was associated with mask discomfort [19]. Similarly, Calderini found mask discomfort as a reason for the cessation of treatment [20]. In our study, patients who received HFO had significantly better dyspnea and comfort scores. We analyzed only a specific group with BMI $>30 \mathrm{~kg} / \mathrm{m}^{2}$, and this is emphasized to be the explanation of better dyspnea and comfort scores with HFO. Obese patients spend more effort on breathing and are more vulnerable to hypoxia. Thus, adequate oxygenation is mandatory to improve symptoms. Moreover, the treatment failure rate was higher with mask $\mathrm{O}_{2}$ and may have contributed to lower dyspnea and comfort scores in our patients.

Although the current study is a prospective randomized study in which we investigated the efficiency of HFO and compared HFO with conventional mask $\mathrm{O}_{2}$ in the postoperative period of obese patients who underwent open heart surgery, the research has certain limitations. The sample size in both groups in the study is modest. The cost of mask $\mathrm{O}_{2}$ and HFO treatments in obese patients was not investigated. Lastly, we have only evaluated the short-term results of both treatment modalities in statistically similar groups, and further researches with long-term follow-up outcomes may be helpful to strongly support the superiority of the technique to another.

In conclusion, we demonstrated that HFO therapy following $\mathrm{CPB}$ in obese patients improved postoperative $\mathrm{PaO}_{2}, \mathrm{SpO}_{2}$, and $\mathrm{PaCO}_{2}$ values and decreased atelectasis scores, reintubation, and mortality rates when compared 
TABLE 4: Comparison of spirometric parameters and dyspnea and comfort scores between groups.

\begin{tabular}{|c|c|c|c|}
\hline & \multicolumn{2}{|c|}{ Group } & \multirow{2}{*}{$p$ value } \\
\hline & Mask $\mathrm{O}_{2}(n=50)$ & High-flow $\mathrm{O}_{2}(n=50)$ & \\
\hline Preoperative $\mathrm{FEV}_{1}{ }^{*}$ & $2.1 \pm 0.2$ & $2.0 \pm 0.2$ & 0.650 \\
\hline Preoperative FVC* & $2.4 \pm 0.5$ & $2.5 \pm 0.5$ & 0.228 \\
\hline Postoperative $\mathrm{FEV}_{1}{ }^{*}$ & $1.0 \pm 0.2$ & $1.1 \pm 0.3$ & 0.292 \\
\hline Postoperative $\mathrm{FVC}^{*}$ & $1.1 \pm 0.4$ & $1.8 \pm 0.4$ & $<0.001$ \\
\hline \multicolumn{4}{|l|}{ Dyspnea score (1st day) } \\
\hline Improvement & $19(38 \%)$ & $32(64 \%)$ & $<0.001$ \\
\hline No improvement & $20(40 \%)$ & $11(22 \%)$ & - \\
\hline Deterioration & $11(22 \%)$ & $7(14 \%)$ & - \\
\hline \multicolumn{4}{|l|}{ Dyspnea score (2nd day) } \\
\hline Improvement & $27(54 \%)$ & $41(82 \%)$ & $<0.001$ \\
\hline No improvement & $17(34 \%)$ & $6(12 \%)$ & - \\
\hline Deterioration & $6(12 \%)$ & $3(6 \%)$ & - \\
\hline Comfort score (1st day) & $2.34 \pm 1.65$ & $3.79 \pm 1.87$ & 0.002 \\
\hline Comfort score (2nd day) & $2.74 \pm 1.45$ & $4.05 \pm 1.76$ & 0.001 \\
\hline
\end{tabular}

${ }^{*}$ Mean \pm standard deviation; $\mathrm{FEV}_{1}$ : forced expiratory volume; FVC: forced vital capacity.

with standard mask $\mathrm{O}_{2}$. Moreover, obese patients achieved significantly better dyspnea and comfort scores following HFO. Our findings could be supported by further prospective, randomized studies with larger patient volume.

\section{Abbreviations}

CPB: Cardiopulmonary bypass

HFO: High-flow $\mathrm{O}_{2}$

ICU: Intensive care unit

SBT: $\quad$ Spontaneous breathing trial

PEEP: Positive end-expiratory pressure

$\mathrm{FiO}_{2}$ : Fraction of inspired oxygen

$\mathrm{PaO}_{2}$ : Arterial pressure of oxygen

$\mathrm{SpO}_{2}$ : Peripheral oxygen saturation

$\mathrm{PaCO}_{2}$ : Arterial partial pressure of carbon dioxide

RAS: Radiological atelectasis score system

CPAP: Continuous positive airway pressure

$\mathrm{FEV}_{1}$ : Forced expiratory volume

FVC: Forced vital capacity

Min: Minutes.

\section{Conflicts of Interest}

The authors declare that they have no conflicts of interest.

\section{References}

[1] G. de Simone, R. B. Devereux, M. Chinali et al., "Prognostic impact of metabolic syndrome by different definitions in a population with high prevalence of obesity and diabetes: The Strong Heart Study," Diabetes Care, vol. 30, no. 7, pp. 18511856, 2007.

[2] J. Krzysztoszek, E. Wierzejska, and A. Zielińska, "Systematic review obesity. An analysis of epidemiological and prognostic research," Archives of Medical Science, vol. 1, pp. 24-33, 2015.
[3] P. S. Choban and L. Flancbaum, "The impact of obesity on surgical outcomes: a review," Journal of the American College of Surgeons, vol. 185, no. 6, pp. 593-603, 1997.

[4] P. Matte, L. Jacquet, M. Van Dyck, and M. Goenen, "Effects of conventional physiotherapy, continuous positive airway pressure and non-invasive ventilatory support with bilevel positive airway pressure after coronary artery bypass grafting," Acta Anaesthesiologica Scandinavica, vol. 44, no. 1, pp. $75-81,2000$.

[5] G. F. Zhu, D. J. Wang, S. Liu, M. Jia, and S. J. Jia, "Efficacy and safety of noninvasive positive pressure ventilation in the treatment of acute respiratory failure after cardiac surgery," Chinese Medical Journal, vol. 126, pp. 4463-4469, 2013.

[6] F. Stéphan, B. Barrucand, P. Petit et al., "High-flow nasal oxygen vs noninvasive positive airway pressure in hypoxemic patients after cardiothoracic surgery: a randomized clinical trial," JAMA, vol. 313, no. 23, pp. 2331-2339, 2015.

[7] R. L. Parke, S. P. McGuinness, D. Milne, and A. Jull, "A new system for assessing atelectasis on chest X-ray after sternotomy for cardiac surgery," Medical Imaging and Radiology, vol. 2, no. 1, p. 2, 2014.

[8] A. Corley, L. R. Caruana, A. G. Barnett, O. Tronstad, and J. F. Fraser, "Oxygen delivery through high-flow nasal cannulae increase end-expiratory lung volume and reduce respiratory rate in post-cardiac surgical patients," British Journal of Anaesthesia, vol. 107, no. 6, pp. 998-1004, 2011.

[9] E. Blouw, A. Rudolph, B. Narr, and M. Sarr, "The frequency of respiratory failure in patients with morbid obesity undergoing gastric bypass," AANA Journal, vol. 71, pp. 45-50, 2003.

[10] T. Gaszynski, W. Gaszynski, and J. Strzelczyk, "Critical respiratory events in morbidly obese," Twoj Magazyn Medyczny Chirurgia, vol. 3, pp. 55-58, 2003.

[11] R. W. Costello, R. Liston, and W. T. McNicholas, "Compliance at night with low flow oxygen therapy: a comparison of nasal cannulae and Venturi face masks," Thorax, vol. 50, no. 4, pp. 405-406, 1995.

[12] N. Schwabbauer, B. Berg, G. Blumenstock, M. Haap, J. Hetzel, and R. Riessen, "Nasal high-flow oxygen therapy in patients with hypoxic respiratory failure: effect on functional and subjective respiratory parameters compared to conventional 
oxygen therapy and non-invasive ventilation (NIV)," BMC Anesthesiology, vol. 14, no. 1, p. 66, 2014.

[13] V. Lemiale, M. Resche-Rigon, D. Mokart et al., "High-flow nasal cannula oxygenation in immunocompromised patients with acute hypoxemic respiratory failure: a groupe de recherche respiratoire en réanimation onco-hématologique study," Critical Care Medicine, vol. 45, no. 3, pp. 274-280, 2017.

[14] S. M. Maggiore, F. A. Idone, R. Vaschetto et al., "Nasal highflow versus Venturi mask oxygen therapy after extubation. Effects on oxygenation, comfort, and clinical outcome," American Journal of Respiratory and Critical Care Medicine, vol. 190, no. 3, pp. 282-288, 2014.

[15] N. Rittayamai, J. Tscheikuna, and P. Rujiwit, "High-flow nasal cannula versus conventional oxygen therapy after endotracheal extubation: a randomized crossover physiologic study," Respiratory Care, vol. 59, no. 4, pp. 485-490, 2014.

[16] S. Suzuki, G. M. Eastwood, M. D. Goodwin et al., "Atelectasis and mechanical ventilation mode during conservative oxygen therapy: a before-and-after study," Journal of Critical Care, vol. 30, no. 6, pp. 1232-1237, 2015.

[17] A. Zarbock, E. Mueller, S. Netzer, A. Gabriel, P. Feindt, and D. Kindgen-Milles, "Prophylactic nasal continuous positive airway pressure following cardiac surgery protects from postoperative pulmonary complications: a prospective, randomized, controlled trial in 500 patients," Chest, vol. 135, no. 5, pp. 1252-1259, 2009.

[18] C. Delclaux, E. L'Her, C. Alberti et al., "Treatment of acute hypoxemic nonhypercapnic respiratory insufficiency with continuous positive airway pressure delivered by a face mask: a randomized controlled trial," JAMA, vol. 284 , no. 18 , pp. 2352-2360, 2000.

[19] N. Kramer, T. J. Meyer, J. Meharg, R. D. Cece, and N. S. Hill, "Randomized, prospective trial of noninvasive positive pressure ventilation in acute respiratory failure," American Journal of Respiratory and Critical Care Medicine, vol. 151, no. 6, pp. 1799-1806, 1995.

[20] E. Calderini, M. Confalonieri, P. G. Puccio, N. Francavilla, L. Stella, and C. Gregoretti, "Patient-ventilator asynchrony during noninvasive ventilation: the role of expiratory trigger," Intensive Care Medicine, vol. 25, no. 7, pp. 662-667, 1999. 


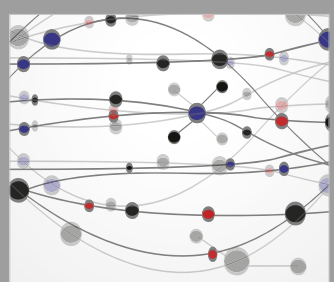

The Scientific World Journal
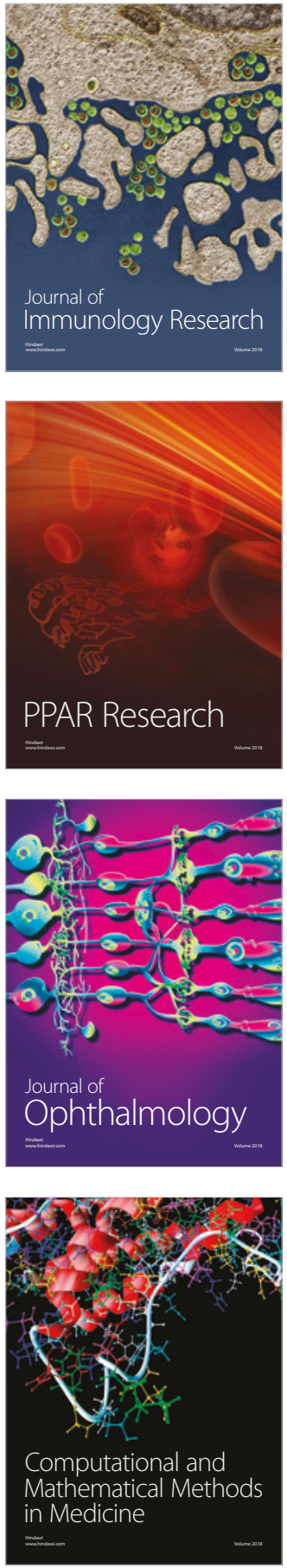

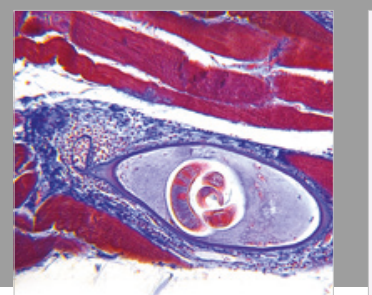

Gastroenterology Research and Practice

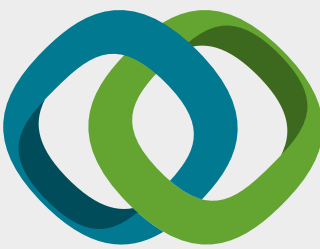

\section{Hindawi}

Submit your manuscripts at

www.hindawi.com
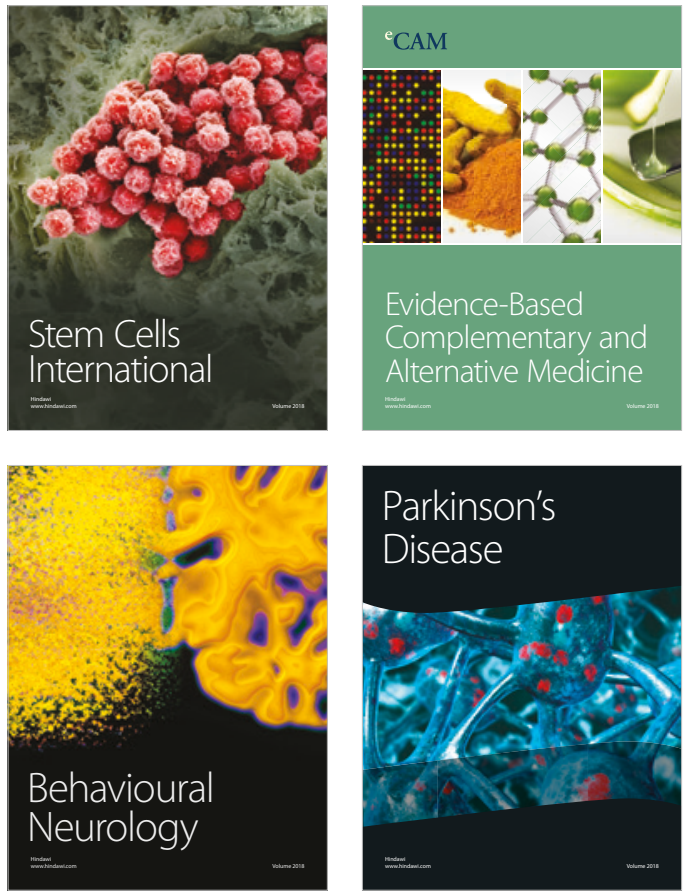

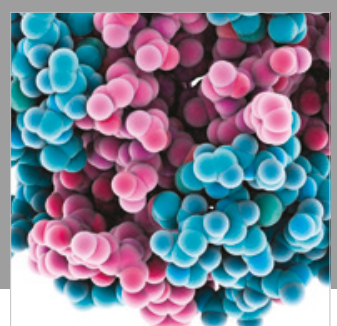

ournal of

Diabetes Research

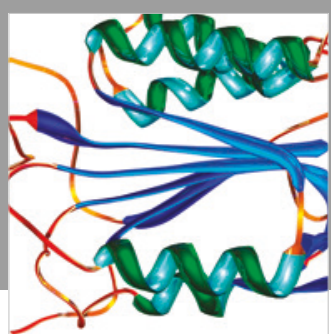

Disease Markers
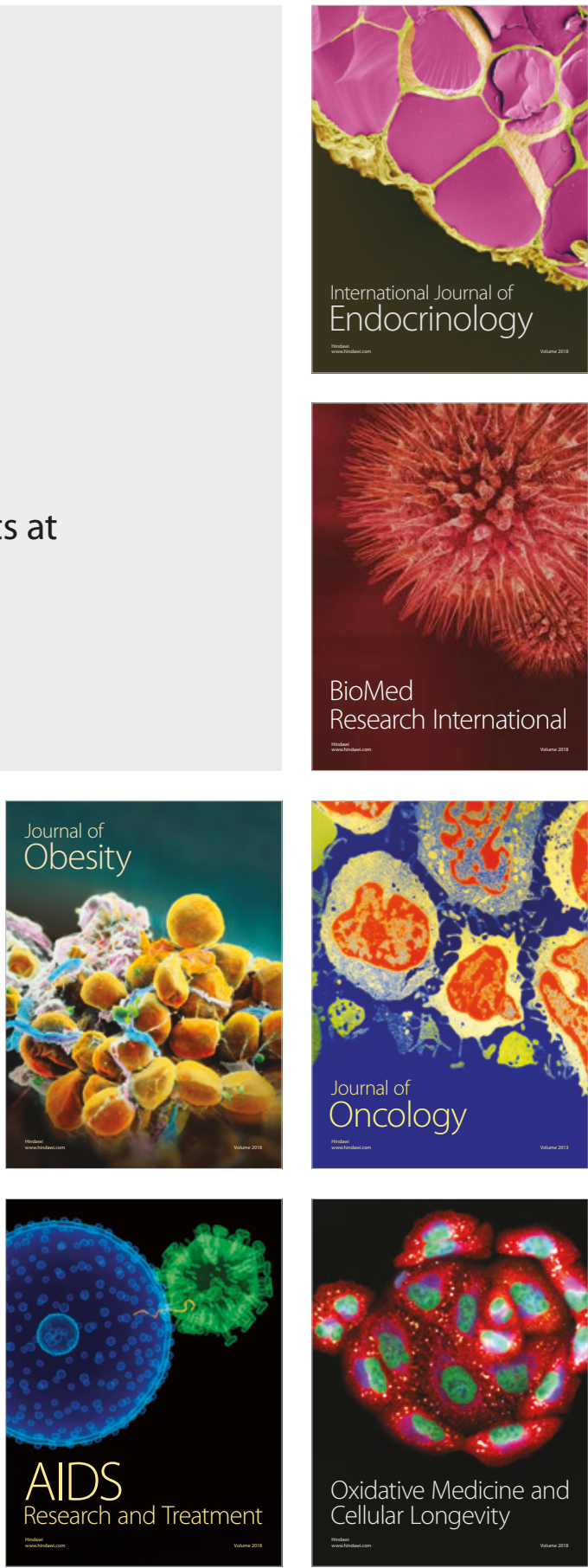